\title{
A sustentabilidade, a educação ambiental e o curso de Educação do Campo: é possível essa aproximação?
}

Juliana Pereira de Araújo ${ }^{1}$, Maria Paulina de Assis ${ }^{2}$, Elis Regina da Costa ${ }^{3}$

${ }^{1}$ Universidade Federal de Goiás - UFG. Regional Catalão. Unidade Acadêmica Especial de Educação. Avenida Dr. Lamartine Pinto de Avelar, 1120. Catalão - GO. Brasil. juliana.barrado@ gmail.com. ${ }^{2}$ Universidade Federal de Goiás - UFG. ${ }^{3}$ Universidade Federal de Goiás - UFG.

RESUMO. O Curso de Licenciatura em Educação do Campo com habilitação em Ciências da Natureza da Universidade Federal de Goiás - Regional Catalão foi criado em 2014 e desde então enfrenta desafios para sua consolidação. Para além das de efetivação de um novo desenho curricular e da formação dos professores formadores que também se aproximam das questões do campo, percebemos a partir de nossa prática cotidiana a necessidade de estabelecermos ancoragem em conceitos e teorias que de fato atuem em benefício do próprio projeto de formação para o campo. É neste sentido, da ausência de ancoragens, que realizamos um estudo reflexivo sobre $\mathrm{o}$ conceito de sustentabilidade buscando tanto a compreensão sobre o mesmo como a avaliação das possibilidades de sua utilização como norteador da prática ou inspiração teóricometodológica. O resultado deste estudo indica que o conceito de sustentabilidade é mais complexo do que parece e exige maior compreensão, contudo consideramos que derivam dele possibilidades que devem ser admitidas como a assunção de outro papel para a educação na dimensão do desenvolvimento sustentável.

Palavras-chave: Sustentabilidade, Educação, Licenciatura em Educação do Campo. 


\title{
Sustainability and the Rural Education Course: is such approach possible?
}

\begin{abstract}
The Licentiate Course in Rural Education with a degree in Nature Sciences from the Federal University of Goiás - Region Catalão was created in 2014 and since then has been facing challenges for its consolidation. Besides the implementation of a new curriculum design and the training of teacher trainers who also approach field issues, we notice from our daily practice the need to establish anchorage in concepts and theories that actually act for the benefit of the project itself in training for the field. It is in this context, from the absence of anchorages, that we carry out a reflexive study about the concept of sustainability, seeking both the understanding about it and the evaluation of the possibilities of its use as a guide to the practice or theoretical-methodological inspiration. The result of this study indicates that the concept of sustainability is more complex than it seems and requires greater understanding, however, we consider that it derives from it possibilities that should be admitted as the assumption of another role for education in the dimension of sustainable development.
\end{abstract}

Keywords: Sustainability, Education, Rural Education. 


\section{La sostenibilidad, La Educación Ambiental y El Curso de Educación Del Campo: ¿Es posible esta aproximación?}

RESUMEN: El Curso de Licenciatura en Educación del Campo con habilitación en Ciencias de la Naturaleza de la Universidad Federal de Goiás Regional Catalán fue creado en 2014 y desde entonces enfrenta desafíos para su consolidación. Además de las de efectivización de un nuevo diseño curricular y de la formación de los profesores formadores que también se acercan a las cuestiones del campo percibimos a partir de nuestra práctica cotidiana la necesidad de establecer anclaje en conceptos y teorías que de hecho actúen en beneficio del propio proyecto de formación para el campo. Es en este sentido, de la ausencia de anclajes, que realizamos un estudio reflexivo sobre el concepto de sustentabilidad buscando tanto la comprensión sobre el mismo como la evaluación de las posibilidades de su utilización como orientador de la práctica o inspiración teóricometodológica. El resultado de este estudio indica que el concepto de sostenibilidad es más complejo de lo que parece y exige mayor comprensión, pero consideramos que derivan de él posibilidades que deben ser admitidas como la asunción de otro papel para la educación en la dimensión del desarrollo sostenible.

Palabras clave: Sostenibilidad, Educación, Licenciatura en Educación del Campo. 


\section{Introdução}

Inúmeros desafios estão colocados aos cursos de Licenciatura em Educação do Campo. Temos como avaliação, a percepção de que assim como a própria Educação do Campo, eles já nascem pagando o preço de todo um acúmulo histórico que perfaz o "campo"i como espaço tocado pela noção de descaso, pela fragilidade em refrear o desvio de suas riquezas naturais, pela discriminação ou por todos os três.

Ademais, ele é impactado por um desafio que é o da escassez de conceitos, de discursos e/ou perspectivas que possam fundamentar uma tal práxis docente com compleição própria e devidamente circunstanciada. Trazendo essa questão ao concreto, o que queremos apontar é que nos falta dizeres ou discurso que se imponham àqueles que colocam o urbano, sua cultura e modo de vida e produção como objetivos centrais e finais do processo de escolarização. Assim, frases ouvidas por tantas e tantas gerações como: "Estude mesmo para ser alguém na vida, ter um bom emprego em boa empresa!", ou "Estudando bem com certeza há de morar na cidade" promovem um discurso e, portanto, práticas das quais não intentamos reproduzir.
É esse desconforto que origina este artigo. Sensação intelectual que exprime o sentimento de formadoras de professores inseguras em relação ao processo de construção de um projeto de formação e tudo aquilo que o envolve, sobretudo o discurso. É, portanto, nosso problema seminal a ausência de ideias que não soem utópicas tampouco soem alheias ao modo desigual como a sociedade se alicerça, mas que encerrem possibilidades concretas de rumo, norteamento para o Curso de Educação do Campo.

Esclarecidas a respeito daquilo que nos incomodava, passamos a analisar os sentidos em torno da ideia de "campo" e percebemos numa primeira avaliação que eles se aproximam da ideia de natureza, que por seu turno se direciona rumo a duas possibilidades: uma associação com o exótico, que com o tempo foi sendo assumida como espaço intocável, quase "sagrado" (como as florestas tropicais e demais biomas), e outra é a associação com a terra, lugar de cultivo e criação ou o que chamamos de roça. E na ordem de ser "terra" foi logo considerada como dispositivo fundamental ao capitalismo (ativo) que submetida ao modo como o sistema produtivo a tratou ao longo de sua evolução foi sendo expurgada dos sentidos de lar, de lugar de cultura, tradição. 
No avançar da história essa díade natureza-campo foi assumindo múltiplas interpretações. Primeiro, como espaço de vida e produção quase sempre em lentes ora romanceadas e em geral empobrecidas, portanto estereotipadas. Segundo, tal qual espaço de produção (a reboque do discurso da modernização agrícola) prestes a adentrar ao mundo moderno, pressupondo neste acesso a lógica de menos homens e mais máquinas. Hoje, particularmente no centro-sul nacional outros termos se associam a ela como "agro", "country" e tantos outros na ordem do bucólico que registramos em placas de entrada de pequenas propriedades como "remanso", "refúgio", "aconchego" etc. Campo e natureza se fundem nessas dissonâncias interpretativas que nos parecem ser verdadeiras esquizofrenias discursivas. Parecem envelopamentos permitidos e supervisionados assumidos em palatabilidade inofensiva. Discursos que compõem o roteiro mor produzido pelo progresso, pela modernidade. Certamente é sinopse que não oferece solidez suficiente para projetarmos o Curso de Educação do Campo por ser via de mão única. São problematizações desse teor que nos mobilizam no sentido de analisar ou rever nossos roteiros.

No primeiro semestre de 2017, durante o desenvolvimento da disciplina
"Didática" o termo sustentabilidade logrou aparecer e se destacar como inspiração aos planos de ensino, aos projetos pedagógicos elaborados. A leitura dos textos produzidos pelos alunos o revelou como um amparo, como um rumo para produzir a prática docente, para repensar o campo e natureza em outra perspectiva.

Embora seja um termo costumeiro aos nossos ouvidos, tivemos uma desconfiança de traço teórico, pedagógico e até mesmo filosófico e nos questionamos: o conceito de sustentabilidade é pertinente ao Curso de Educação do Campo em que atuamos? Como ele se constitui enquanto ideiadiscurso e o que revela?

Essas questões justificaram a realização do estudo que origina este artigo. Para a estrutura do texto em questão partimos da apresentação do lugar de onde falamos, que é o Curso de Educação do Campo da Universidade Federal de Goiás. Em seguida, apresentamos um sobrevoo histórico do conceito de sustentabilidade não intentando extingui-lo ou cobri-lo por completo, mas sim buscando exprimir pistas sobre o mesmo. Há na sequência a apresentação de algumas análises sobre o conceito de sustentabilidade encontrado na varredura das produções e algumas que ponderam sua relação com a educação, o que é explicitado no front da educação 
ambiental/educação

para

O

desenvolvimento

sustentável.

Exploraremos, ao final, as implicações da utilização deste discurso no curso de Licenciatura em Educação do Campo na UFG-Catalão. Finalmente, tecemos nossas considerações retomando a pergunta de partida.

\section{O curso de Licenciatura em Educação do Campo da UFG-Catalão}

O surgimento da Licenciatura em Educação do Campo na Universidade Federal de Goiás- Regional Catalão ocorre na esteira de ações em prol da Educação do Campo desenvolvidas desde 2004. Ações que para a constituição de uma Política Nacional de Educação do Campo foram integradas no Plano nas ações das diferentes Secretarias do Ministério da Educação (MEC). Na dimensão do ensino superior, a Educação do Campo foi alocada no Sistema Universidade Aberta do Brasil (UAB), com oferta de cursos de extensão, aperfeiçoamento e de especialização. Já a formação inicial para educadores do campo foi contemplada no Plano de Ações Articuladas (PAR), com a criação de cursos de Licenciatura em Educação do Campo que por sua vez foi fortalecida pelo Programa de Apoio à Formação Superior em Licenciatura em Educação do Campo (Procampo), realizado pela Secretaria de Educação Continuada, Alfabetização, Diversidade e Inclusão (Secadi). O objetivo do Procampo é apoiar a implementação de cursos regulares de Licenciatura em Educação do Campo nas instituições públicas de ensino superior de todo o país, voltados especificamente para a formação de educadores para a docência na segunda etapa do Ensino Fundamental $\left(6^{\circ}\right.$ ao $9^{\circ}$ ano) e Ensino Médio ( $1^{\circ}$ ao $3^{\circ}$ ano), de maneira regular e na modalidade de Educação de Jovens e Adultos em áreas do conhecimento escolar relacionadas às Ciências da Natureza.

Em 2008, quatro universidades federais (Universidade de Brasília; Universidade Federal da Bahia; Universidade Federal de Minas Gerais; Universidade Federal de Sergipe) abriram as primeiras turmas. Em 2012, ocorreu a publicação de Chamada Pública de seleção $\mathrm{N}^{\circ}$ 2/2012 - SESU/SETEC/SECADI/MEC para que Instituições apresentassem suas proposições para cursos de Licenciatura em Educação do Campo. No estado de Goiás foram aprovados dois cursos, ambos pela Universidade Federal Goiás (UFG), um na Regional Catalão e outro na Regional Cidade de Goiás.

As turmas da Regional Catalão foram abertas em 2014, oferecendo a habilitação em Ciências da Natureza e 
tendo como diferencial o esforço coletivo para que o processo educativo se baseie em uma perspectiva interdisciplinar que rompa a perspectiva reducionista e fragmentária pela qual o campo é perpetuado como lugar de precariedade (Alves \& Faleiro, 2015). A adoção da interdisciplinaridade atua assim, no sentido de diminuir as fronteiras que cindem a perspectiva social em dicotomias do tipo rural $\mathrm{x}$ urbano, campo-cidade. A expectativa é que professores formados nestas bases atuem criticamente ante uma cultura escolar urbanocêntrica que direciona suas ações no rumo da formação para o mercado de trabalho unicamente. A metodologia da Alternância é elemento que manifesta a interdisciplinaridade como eixo. Ela consiste em dividir o período letivo em dois tempos, sendo um o 'Comunidade' e o outro o 'Universidade' (Costa, Alves \& Faleiro, 2015) traduzindo os esforços por um processo formativo mais complexo e real. Esse modelo, que é o da alternância, se ampara no intento de garantir aos estudantes residentes no campo a permanência em seu espaço para que não percam o vínculo com sua cultura camponesa, portanto evitando que tenham que se mudar permanentemente para as cidades (Alves \& Faleiro, 2015).

Discutindo os desafios do curso, Faleiro \& Farias (2016) destacam que a constituição de um grupo de professores instrumentalizados a partir de uma lógica mais plausível e concreta é algo central. Concordamos com tais autores e ponderamos que esse desafio tem conexão com o desconforto que originou nosso estudo sobre a sustentabilidade, já que entendemos que parte dessa instrumentalização deveria ocorrer na dimensão do discurso pela adoção de termos, conceitos ou ideias. Movimento contributivo para que o pensamento sobre o "campo" e sobre o Curso de Educação do Campo encontre caminho fora dos limites do bucólico, do tranquilo ou do precário.

Como ressalvam Alves \& Faleiro (2015), é necessário fugirmos da consonância de que é preciso fixar o homem ao campo assim como da de que o rural se resume ao agrícola. Nestas delimitações, que são concretas, não seria possível para nós adotarmos o discurso da formação para os professores de Ciências da Natureza para os povos dos campos que se articulam na rasura ou parcialidade de tê-lo como opção secundária. Pior seria adotarmos a linha do "campo" como "bucólico", como "lugar de paz" porque isso seria reduzi-lo e acoplá-lo ao modelo vigente pelo expediente de imobilizá-lo em bases idílicas de caracterização.

Sobre a sustentabilidade 
O conceito de sustentabilidade tem duas origens distintas. Uma primeira fincada na biologia através da ecologia e uma segunda ancorada na economia. Essa, projetando a perspectiva de que o padrão de consumo e produção consolidados nos últimos tempos não deverá perdurar devido ao esgotamento dos recursos naturais. Aquela, preocupada com a capacidade de recuperação e reprodução dos ecossistemas em face das agressões antrópicas ou mesmo naturais que contingenciam a exploração de nossos recursos. (Baroni, 1992; Mikhailova, 2004; Nascimento, 2012).

A literatura evidencia que a ideia de sustentabilidade embora já existisse como preocupação desde a década de 1950 (Nascimento, 2012) e houvesse se consolidado através da ação dos movimentos ambientalistas na década de 1970 (Lima, 2003) teria se circunstanciado de fato entre fins dos anos de 1970 e 1980 (Baroni, 1992; Lima, 2003; Mikhailova, 2004; Nascimento, 2012) já que é nesse período que se dá a admissão mais ampla da existência de uma crise ambiental. É essa admissão que embasa a realização de conferências como a de Estocolmo em 1972, que colocaram frente a frente países dos então chamados primeiro mundo e terceiro mundo preocupados com a degradação ambiental.
Jacobi (2005), citando Nobre e Amazonas (2002), esclarece que é nesta fase que o termo vai se fortalecendo como “desenvolvimento sustentável”, demarcando "a necessidade de se elevar a problemática ambiental a um plano de visibilidade na agenda política internacional e fazer com que a temática penetre e conforme as decisões sobre políticas em todos os níveis" (p. 235). Ainda segundo Jacobi (2005), vemos que duas correntes interpretativas emergem ao longo deste processo. Uma corrente econômica e técnico-científica que sugere a articulação do crescimento econômico e a preservação ambiental influindo em modificações nas abordagens do desenvolvimento econômico, notadamente a partir dos anos de 1970. Outra corrente, ecoante da crítica ambientalista ao estilo de vida contemporâneo que é a que se difunde a partir da Conferência de Estocolmo em 1972 realizada em meio ao impacto provocado pelo relatório do clube de Roma $^{\mathrm{ii}}$ que propunha o desaceleramento do desenvolvimento dos países desenvolvidos e do crescimento populacional nos subdesenvolvidos. Na avaliação do autor o que se sucede com o passar do tempo é o descarte de ambas as posições e o surgimento de uma posição intermediária estabelecida entre o economicismo determinista cuja prioridade é o 
crescimento econômico e o fundamentalismo ecológico (inevitabilidade do crescimento do consumo e esgotamento dos recursos naturais). O paradigma do caminho do meio é o chamado ecodesenvolvimento ou desenvolvimento sustentável que propunha um desenvolvimento que harmonizasse os objetivos sociais, ambientais e econômicos. É essa via que se consagra na Rio-92.

Retomando a cronologia estruturada pelo sobrevoo sobre a sustentabilidade ou desenvolvimento sustentável, o que a literatura sugere é que a complexidade e vigor das discussões foram razões para que a Organização das Nações Unidas (ONU) criasse uma comissão técnica que elaborou, em 1973, o documento Only one Hearth no qual se indicava que o problema ambiental decorria, de um lado, de externalidades econômicas próprias do modelo de desenvolvimento (tecnologia agressiva e consumo excessivo) e, de outro, da falta de desenvolvimento (crescimento demográfico e baixo PIB).

Muitas publicações alimentam e encaminham a discussão, como o documento Estratégia de Conservação Mundial com o objetivo de alcançar o desenvolvimento sustentável através da conservação dos recursos vivos publicado em 1980, a União Internacional para a
Conservação da Natureza (UICN) e a Carta de Ottawa (escrita ao final da Conferência de Ottawa em 1986) que estabeleceu cinco requisitos para se alcançar o desenvolvimento sustentável: a) integração da conservação e do desenvolvimento; b) satisfação das necessidades básicas humanas; c) alcance de equidade e justiça social; d) provisão da autodeterminação social e da diversidade cultural; e) manutenção da integração ecológica (Baroni, 1992).

A Conferência das Nações Unidas para o Meio Ambiente e o Desenvolvimento realizada em 1992 (após a aprovação da convocação pela Assembleia das Nações Unidas e 1989) que ficou conhecida como Rio-92 (o Rio de Janeiro foi sede do evento) marca o auge das discussões e conferencias. A conferência teve a presença de 173 chefes de Estado e dela se originou o documento “Agenda 21", pretendendo guiar o planeta na rota do desenvolvimento sustentável. $\mathrm{Na}$ mesma ocasião, foram aprovados outros dois importantes e complementares documentos para uma sociedade "sustentável" a Carta da Terra e o Tratado da Educação Ambiental para as Sociedades Sustentáveis. É como resultado direto da Rio-92 que é promulgada no Brasil a Lei 9.795, de 27 de abril de 1999, que dispõe sobre a educação ambiental e institui a 
Política Nacional de Educação Ambiental definindo que a educação ambiental se concretiza em processos por meio dos quais o indivíduo e a coletividade constroem valores sociais, conhecimentos, habilidades, atitudes e competências voltadas para a conservação do meio ambiente, bem de uso comum do povo, essencial à sadia qualidade de vida e sua sustentabilidade.

Outro marco institucional e de norteamento foi a publicação da resolução que definiu a Década das Nações Unidas da Educação para o Desenvolvimento Sustentável de 2005 a 2014, que foi uma ação aprovada pela Assembleia Geral das Nações Unidas por meio da resolução $57 / 254$ durante sua $57^{\mathrm{a}}$ Sessão de dezembro de 2002. A iniciativa decorreu do projeto "Educação para um Futuro Sustentável”, criado em 1994 pela organização como o principal mecanismo para a aplicação das recomendações relativas à educação, efetuadas pelas grandes conferências das Nações Unidas na década de 1990 e pelas convenções da diversidade biológica, mudança climática e desertificação. Em 2006 é formado um Grupo de Referência para subsidiar a Secretaria da Década com norteamentos conceituais e de estratégias.

$\mathrm{O}$ que deriva desses encontros e desse processo é o estabelecimento de pontos consensuais como o de que o desenvolvimento sustentável se compõe essencialmente de três dimensões: a ambiental, a econômica e a social. A primeira pressupõe que o modelo de produção e consumo deva ser compatível com a base material em que se assenta a economia, como subsistema do meio natural. Neste prisma a forma de produzir e consumir deve garantir que os ecossistemas mantenham sua autorreparação ou capacidade de resiliência. A segunda que orienta o aumento da eficiência da produção e do consumo com economia crescente de recursos naturais. Trata-se daquilo que se denomina como ecoeficiência, que supõe uma contínua inovação tecnológica que nos leve a sair do ciclo fóssil de energia (carvão, petróleo e gás) e a ampliar a desmaterialização da economia. E a terceira defende todos tenham o mínimo necessário para uma vida digna e ninguém retenha bens, recursos naturais $\mathrm{e}$ energéticos danosos aos outros. Isso quer dizer erradicar a pobreza e "definir o padrão de desigualdade aceitável, delimitando limites mínimos e máximos de acesso a bens materiais. Em resumo, implantar a velha e desejável justiça social” (Nascimento, 2012, p. 55). O outro ponto de confluência repousa na admissão da educação como instrumento 
fundamental para a efetivação do desenvolvimento sustentável.

$\mathrm{Na}$ realização deste estudo o que se mostrou necessário após o sobrevoo histórico (que nos mostrou a existência de um campo de disputa sobre a validação do conceito de desenvolvimento sustentável cartografado entre a visão econômica e a ambiental) foi recorrermos a produções que analisaram as derivações históricas do percurso. São textos que evidenciam que os discursos produzidos são múltiplos e que, portanto, não há uma visão unívoca do termo desenvolvimento sustentável. Pelo contrário, indicam a polifonia do tema e por isso a fragilidade no eixo da definição, o que afeta a efetivação de ações e planos mais objetivos. No bojo de ambiguidades e deficiências se produzem vertentes diferentes sobre a questão e é importante aprofundar nossa compreensão.

Um dos textos fundamentais na análise do conceito de sustentabilidade é o de Baroni que em 1992 (é pioneiro na análise do tema) apontou as ambiguidades e deficiências do conceito de desenvolvimento sustentável a partir de uma revisão de literatura salientando as críticas emergentes. A autora cita especialmente o estudo de Pearce sobre as múltiplas definições do conceito e recorre à análise de Lélé (1991) reforçando a indicação no rumo de um consenso social na definição da sustentabilidade ou pelo menos um conteúdo mais preciso ao termo. Enveredando na análise apresenta a avaliação de Lélé (1991) que encerra a visão de que a corrente principal do desenvolvimento sustentável é a econômica que, contudo, sofre de três fraquezas: a primeira é a que deriva do fato de que a relação entre degradação ambiental e pobreza é biunívoca, ou seja, a pobreza leva a degradação e a degradação à pobreza. A segunda é a deficiência sobre suas conceituações sobre os objetivos do desenvolvimento e da participação e a terceira a incerteza e falta de conhecimento que imperam, já que Baroni (1992) nota que "os conceitos de sustentabilidade e participação são articulados pobremente, tornando difícil determinar se um projeto de desenvolvimento particular promove ou não uma forma particular de sustentabilidade" (Baroni, 1992, p. 20).

$\mathrm{Na}$ conclusão do texto uma frase explicita bem o que Baroni percebeu ao analisar as ambiguidades e deficiências do conceito de desenvolvimento sustentável. A frase é a seguinte:

É possível já concluir que, muitas vezes, sustentabilidade ecológica, desenvolvimento sustentável e sustentabilidade são usados com os mesmos sentidos, embora tenham significados distintos. $\mathrm{O}$ que se pode concluir, também, é que muitos autores se propõem definir desenvolvimento sustentável e, no 
entanto, apresentam propostas genéricas e setoriais demais. (Baroni, 1992, p. 22).

Benfica (2008) também contribui para desnaturalização da ideia de sustentabilidade ou desenvolvimento sustentável. Pelo seu artigo ele se propõe a discutir a concepção de sustentabilidade, a partir das perspectivas de Altvater (1995) e Sachs (2000) e se pergunta sobre o modelo educacional exigido pelo atual momento de crise ecológica. Assim como em Baroni (1992), há neste escrito uma crítica estruturada na direção de ver a teoria do desenvolvimento sustentável como uma “fórmula vazia". Citando Altvater (1995) o autor pontua que a maior contradição da proposta do desenvolvimento sustentável é de que a organização das estruturas econômicas e sociais só se permite serem sustentáveis de modo condicional, ou seja, somente enquanto não se chocam com as restrições sistêmicas externas, sobretudo o princípio do lucro. A conclusão é simples e realista já que "ser sustentável constitui norma digna de ser efetivada, mas que só se pode converter em realidade na medida em que as instituições básicas da sociedade sejam modificadas". (Altvater, 1995, p. 295-296 apud Benfica, 2008). O que nos chamou a atenção foi a reflexão de Altvater apresentada por Benfica sobre o termo desenvolvimento sustentável e que merece ser exposta tal qual colocada por este último autor. Benfica expõe que na perspectiva de Altvater

O conceito de "desenvolvimento" não é um conceito neutro. Ele tem um contexto bem preciso dentro de uma ideologia do progresso, que supõe uma concepção de história, de economia, de sociedade e do próprio ser humano. O conceito foi utilizado numa visão colonizadora, durante muitos anos, na qual os países do globo foram divididos entre "desenvolvidos", "em desenvolvimento" e "subdesenvolvidos", remetendo-se sempre a um padrão de industrialização e de consumo. Ou seja, existe uma incompatibilidade de princípios entre sustentabilidade e capitalismo. O fracasso da Agenda 21 o demonstra. (Benfica, 2008, p. $5)$.

Carletto, Linsingen e Delizoicov (2006) se alinham às ideias expostas por Benfica e apresentam as "polêmicas" em torno do desenvolvimento sustentável trazendo considerações de vários autores como Leff (2001) e Montibeller Filho (2004). Após o diálogo com tais autores, chegam a conclusão que:

As evidências apontam para a impossibilidade do sistema capitalista envolver-se de forma intensiva com desenvolvimento sustentável, com suas dimensões básicas de equidades intrageracional (garantia de qualidade de vida a todos), intergeracional (garantia de recursos para as próximas gerações) e internacional (de todos os indivíduos independente de sua localização geográfica). (Carletto, Linsingen \& Delizoicov, 2006, p. 7). 
O que podemos salientar dessas leituras é a complexidade de nos posicionarmos em relação ao desenvolvimento sustentável ou sua projeção. E não há como fugir a essa situação por sermos educadores. Mesmo porque a educação vai se colocando como elemento central a questão. De algum modo o desenvolvimento sustentável e/ou a sustentabilidade veem na educação elemento fundamental.

\section{Educação e sustentabilidade}

Foi possível percebermos que o debate educacional sobre 0 desenvolvimento sustentável se fortalece pari passu ao debate maior sobre o próprio conceito. De modo mais preciso Carletto, Linsingen e Delizoicov (2006) informam que o reconhecimento do valor da educação para o desenvolvimento sustentável se materializou no lançamento da Década da Educação para o Desenvolvimento Sustentável (2005-2014) promovida pela Organização das Nações Unidas - ONU e liderada pela Organização das Nações Unidas para a Educação, Ciência e Cultura - UNESCO.

Ao analisarmos a literatura sobre educação ambiental descobrimos que ela é marcada por "polêmicas", "ambiguidades" e "deficiências" a espelho do que acontece com o conceito-discurso de desenvolvimento sustentável. Desde nossas primeiras aproximações com a temática percebemos uma profusão de terminologias como educação ambiental, ecopedagogia, educação para sustentabilidade (EpS) e outros.

A leitura do artigo de Carletto, Linsingen e Delizoicov (2006) nos comprovou que de fato a multiplicidade das propostas é fruto da dispersão de definições a respeito do que seria a educação voltada ou alinhada ao desenvolvimento sustentável quando sustentam que as diferentes interpretações do termo Desenvolvimento Sustentável, estando alocadas no campo do dissenso, da contradição e da ambiguidade, "geram polêmica e indicam que a polissemia discursiva do desenvolvimento sustentável tem favorecido os discursos que defendem o modelo de desenvolvimento hegemônico" (Carletto, Linsingen e Delizoicov, 2006, p. 7). As análises de Crespo (2003) são exploradas para reforçar este ponto de vista e enfatizar que é fragmentada a forma com que os temas ambientais têm sido tratados no âmbito educacional, formal ou informal, e isso "dificulta o desenvolvimento de uma compreensão crítica do Desenvolvimento Sustentável e inibe a efetivação de propostas educacionais transformadoras" 
(Carletto, Linsingen e Delizoicov, 2006, p.

7). O enfoque educacional chamado de Ciência Tecnologia e Sociedade (CTS), por se aproximar da prática educativa transformadora preconizada por Freire (1987), seria um caminho possível já que se objetivaria como uma educação formadora de cidadãos críticos, "detentores de um entendimento mais coerente acerca da ciência e da tecnologia, capazes de intervir ética e democraticamente no mundo" (Carletto, Linsingen e Delizoicov, 2006, p. 9). No encerramento do texto a mensagem que deixam é a da necessidade de vincular a sustentabilidade e a educação à formação de professores. Assim, colocam:

o esforço para a construção de uma percepção de sustentabilidade que busque $o$ fortalecimento dos processos negociados de tomadas de decisão, está intimamente vinculado ao processo pedagógico e requer vigorosa defesa de uma adequada formação de professores em todos os níveis e modalidades de educação. E que esta formação, associada à ideia de uma educação crítica e transformadora do sentir pensar e agir, deve visar à criação de condições que permitam ampliar o poder social dos cidadãos através da construção de consciência crítica, aproximando a educação das condições reais de existência de seus atores (Carletto, Linsingen e Delizoicov, 2006, p. 12).

Sauvé (2005) se mostrou pertinente ao discutir possibilidades e limites à educação ambiental. A pesquisadora destaca que a educação ambiental alcançou posição de destaque ao longo dos anos e que ela não é somente uma forma de educação entre tantas outras ou mera ferramenta para a resolução de problemas ou de gestão do meio ambiente. Ela é "uma dimensão essencial da educação fundamental que diz respeito a uma esfera de interações que está na base do desenvolvimento pessoal e social: a da relação com o meio em que vivemos, com essa "casa de vida" compartilhada" (Sauvé, 2005, p. 317). O objetivo que Sauvé (2005) apresenta para a educação ambiental assume que ela

visa a induzir dinâmicas sociais, de início na comunidade local e, posteriormente, em redes mais amplas de solidariedade, promovendo a abordagem colaborativa e crítica das realidades socioambientais e uma compreensão autônoma e criativa dos problemas que se apresentam e das soluções possíveis para eles. (Sauvé, 2005, p. 317).

Sauvé (2005) afirma que o educador deve considerar as várias facetas da relação com o meio ambiente já que estas orientam maneiras diversas e complementares de apreender o meio ambiente. Na sequência, apresenta algumas dessas maneiras: o meio-ambiente natureza; o meio-ambiente recurso; o meio-ambiente problema; o meio-ambiente sistema; o meio-ambiente lugar onde se vive; o meio-ambiente 
biosfera e o meio-ambiente projeto comunitário. Nessa averiguação há o argumento para compreensão da complexidade do projeto educativo para a educação ambiental. No texto que foi publicado em 2005 quando se iniciava a Década das Nações Unidas para a educação com vistas a um desenvolvimento sustentável há ainda a reflexão que dá conta de que o uso do termo educação para o desenvolvimento sustentável em substituição a educação ambiental orienta uma "concepção utilitarista da educação e a representação "recursista" do meio ambiente, adotada pela educação para o desenvolvimento sustentável" (Sauvé, 2005, p. 320) que se mostram visivelmente reducionistas com relação a uma educação preocupada em otimizar a teia de relações entre as pessoas, o grupo social a que pertencem e o meio ambiente.

Jacobi (2005) também utiliza o termo educação ambiental na mesma ordem de Sauvé (2005), que pressupõe o entendimento de que a educação nesta dimensão deve ser pautada pela crítica e pela emancipação que nem sempre coadunam com o projeto de desenvolvimento hegemonicamente propalado. Jacobi (2005) recusa-se em adotar o termo desenvolvimento para pensar a educação ambiental, pois segundo ele "as tensões entre desenvolvimento e conservação do meio ambiente ainda persistem, e o forte viés economicista é um dos fatores de questionamento do conceito pelas organizações ambientalistas". (Jacobi, 2005, p. 235). É de certa forma uma oposição àquilo que surgiu com mais força após a Rio-92, que foi a maciça expansão do termo desenvolvimento sustentável ainda que para o autor, com base em Nobre e Amazonas (2002), os resultados do evento tenham ficado aquém dos pretendidos pelos organismos proponentes porque a discussão ambiental sofreu na verdade "uma refração" na qual se consagrou a separação entre negociações em torno de acordos ambientais globais e as outras relativas à implementação de projetos de desenvolvimento sustentável de âmbito nacional, notadamente a Agenda 21".

É Jacobi (2005) que ao enveredar pela reflexão de como seria a educação ambiental argumenta mais concretamente em prol de uma perspectiva emancipatória e crítica como ancoragem, sendo esta inspirada em teóricos como Paulo Freire, Snyder e Giroux. No que se refere ao meio ambiente, cita Capra, Morin, Leff, e Boff, dentre outros que propõem uma educação baseada em práticas, orientações e conteúdos que transcendem a preservação ambiental. Ao longo do artigo, fomos 
percebendo uma aproximação entre o que o autor propõe e aquilo que nos guia no interior do projeto político pedagógico do Curso de Educação do Campo em que atuamos. A valorização da interdisciplinaridade é um ponto a se destacar. Jacobi (2005, p. 247) finaliza seu artigo afirmando:

Concluímos afirmando que o desafio político-ético da educação ambiental, apoiado no potencial transformador das relações sociais, encontra-se estreitamente vinculado ao processo de fortalecimento da democracia e da construção de uma cidadania ambiental. Nesse sentido, o papel dos educadores e professores é essencial para impulsionar as transformações de uma educação que assume um compromisso com a formação de uma visão crítica, de valores e de uma ética para a construção de uma sociedade ambientalmente sustentável.

Gadotti (2008) parte de sua análise sobre a sustentabilidade para problematizar a questão da educação. Segundo o autor, ela se divide em dois eixos: um relativo à natureza e outro relativo à sociedade. Ao fazê-lo ultrapassa os limites do ecológico e adentra-nos no social, o que abre possibilidades maiores e mais afeitas à formação de professores. $\mathrm{O}$ eixo da sustentabilidade da natureza se assenta na ideia da sustentabilidade ecológica, ambiental e demográfica (se preocupa então com os recursos naturais e com os ecossistemas). Já o eixo da sustentabilidade social diz respeito à sustentabilidade cultural, social e política. Refere-se à manutenção da diversidade e das identidades diretamente relacionadas com a qualidade de vida das pessoas, da justiça distributiva e ao processo de construção da cidadania e da participação das pessoas no processo de desenvolvimento. Para Gadotti (2008) esse é o eixo que reposiciona os sujeitos e as pessoas ao estabelecer a necessidade da conexão com a história, as identidades, as tradições.

Diferentemente de Sauvé (2005) e Jacobi (2005), Gadotti (2008) utiliza o termo "ecopedagogia", que concebe como movimento social e político surgido no "seio na sociedade civil, nas organizações de educadores, de ecologistas, de trabalhadores e empresários preocupados com o meio ambiente" (Gadotti, 2000, p. 92). O autor a percebe como um movimento social e político inspirado no pensamento freireano (Paulo Freire é considerado um inspirador das ideias ecopedagógicas) que está em processo de formação. Gadotti (2000) lembra que o termo ecopedagogia apareceu em agosto de 1999, durante o I Encontro Internacional da Carta da Terra na Perspectiva da Educação.

Nos alinhamos a Gadotti (2008) na expectativa de que o movimento em prol 
da sustentabilidade influa em reorientações mais profundas que atinjam o nível legal, as reformas educacionais, o curriculum, os conteúdos e o nível pessoal do compromisso. Tal como o autor, acreditamos que Educação para o Desenvolvimento Sustentável (EDS)

\begin{abstract}
implica mudar o sistema, implica o respeito a vida, o cuidado diário com o planeta e cuidado com toda comunidade da vida, da qual a vida humana é um capitulo. Isto significa compartilhar valores fundamentais, princípios éticos e conhecimentos como respeito à terra e a toda diversidade da vida; cuidar da comunidade da vida com compaixão e amor; construção de sociedades democráticas que sejam justas, participativas, sustentáveis e pacíficas. A EDS é um conceito central de um sistema educacional voltado para o futuro (Gadotti, 2008, p. 38).
\end{abstract}

Havendo explorado o conceito de sustentabilidade e melhor compreendido sua relação com a educação. Retomamos as questões que nos moveram na execução do estudo. O conceito de sustentabilidade é pertinente ao Curso de Educação do Campo em que atuamos? Como ela (a sustentabilidade) se constitui enquanto ideia-discurso e o que revelam?

\section{Considerações}

Não damos por finalizada nossa incursão no estudo sobre a sustentabilidade e a educação ambiental. Podemos, contudo, fazer algumas escolhas iniciais, sendo a utilização do termo sustentabilidade uma delas e educação ambiental seu espelho na dimensão da educação. Temos maior clareza sobre a adoção do paradigma da CTS no curso tendo-a como disciplina inclusive.

Isso porque nos foi possível concordar com o que autores como Jacobi (2005) e Sauvé (2005) utilizam em e que manifestam a recusa ao termo desenvolvimento por seu atrelamento reducionista a um modelo econômico e produtivo colonialista que não assume que a sustentabilidade esbarra nas desigualdades sociais. Eventualmente, nos permitimos pensar nela como ecopedagogia e, sobretudo como pedagogia da terra, conforme Gadotti (2008), pois como ele, entendemos o planeta de forma ampla, subjetiva, comunitária.

Entretanto, também podemos e devemos aqui enfatizar que consideramos que é preciso discutir em nossos coletivos os elementos, argumentos, análises aqui expostas e ainda outros mais, sobretudo a forma como a polifonia do discurso da sustentabilidade e da educação ambiental gera ambiguidades ou porque não territorializações de propostas ou visões parciais opressoras ou unilaterais. Devemos problematizar como a 
Licenciatura em Educação do Campo concebe a natureza, como concebe a função dos professores que forma, como concebe uma sociedade sustentável.

Isso não nos impede de engrossar o coro das vozes que defende a sustentabilidade porque no miúdo sabemos que há um esgotamento do modelo ambiental, produtivo e econômico que nos atinge cotidianamente através formas brutais e inequânimes pelas quais acessamos ou deixamos de acessar a riqueza, a educação, a saúde, a renda. A sustentabilidade e consequentemente a educação ambiental podem certamente ser tomadas e defendidas como projeções teóricas, e sabemos agora metodológicas (nos identificamos com a interdisciplinaridade, a emancipação), que nos movem, nos lançam na busca de outra formação e atuação social.

As próximas turmas de Didática provavelmente terão na sustentabilidade ponto de partida para pensar a prática docente e suas relações com o local.

\section{Referências}

Altvater, E. (1995). O preço da riqueza: pilhagem ambiental e a nova (des)ordem mundial. São Paulo: UNESP.

Alves, M., \& Faleiro, W. (2015). A imaginação sociológica e a produção de saberes em comunidades rurais da região de Catalão-GO. Cadernos CIMEAC, 5(1),
91-106.

Doi: https://doi.org/10.18554/cimeac.v5i1.1474

Baroni, M. (1992). Ambiguidade e deficiências do conceito de desenvolvimento sustentável. Rev. Adm. Empr. 32(2), 14-24.

Benfica, G. (2008). Sustentabilidade $e$ Educação. Salvador: Seara.

Carletto, M. R., Linsingen, I., \& Delizoicov, D. (2006). Contribuições a uma educação para a sustentabilidade. In $I$ Congresso Ibero-Americano de Ciência, Tecnologia, Sociedad y Inovación CTS $+I$, Mesa 16, Palácio de Minería.

Costa, E. R., Alves, M. Z., \& Faleiro, W. A. (2015). Interdisciplinaridade no Curso de Educação do Campo: O Caso da UFG Catalão. Enciclopédia Biosfera, 11(20).

Crespo, S. (2003). Uma visão sobre a evolução da consciência ambiental no Brasil nos anos 1990. In Trigueiro, A. (Org.). Meio ambiente no século 21: 21 especialistas falam da questão ambiental nas suas áreas de conhecimento(pp.58-73). Rio de Janeiro, RJ: Sextante.

Edital de Seleção $n^{\circ} \quad 2 / 2012 \quad-$ SESU/SETEC/SECADI/MEC de 31 de agosto de 2012. Chamada pública para seleção de Instituições Federais de Educação Superior - IFES.

Faleiro, W., \& Farias, M. (2016). Formadores de professores em Educação do Campo em Goiás. Revista Brasileira De Educação Do Campo, 1(1), 88-106. Doi: http://10.20873/uft.2525-

$\underline{4863.2016 \mathrm{v} 1 \mathrm{n} 1 \mathrm{p} 88}$

Freire, P. (1987). Pedagogia do oprimido. Rio de Janeiro, RJ: Editora Paz e Terra.

Gadotti, M. (Org). (2000). Perspectivas Atuais da Educação. Porto Alegre: Artmed. 
Gadotti, M. (2008). Educar para Sustentabilidade: Uma contribuição à Década da Educação para o Desenvolvimento Sustentável. São Paulo: Editora L.

Jacobi, P. R. (2005). Educação ambiental: o desafio da construção de um pensamento crítico, complexo e reflexivo. Educação $e$ Pesquisa, 31(2), 233-250. https://dx.doi.org/10.1590/S151797022005000200007

Leff, E. (2001). Epistemologia ambiental. São Paulo, SP: Editora Cortez.

Lélé, S. (1991). Sustainable development: a critical review. World Development. London: Pergamon Press.

Lima, G. C. (2003). O discurso da sustentabilidade e suas implicações para a educação. Ambiente \& Sociedade, 6(2), 99119.

Doi:

http://dx.doi.org/10.1590/S1414753X2003000300007

Mikhailova, I. (2004). Sustentabilidade: evolução dos conceitos teóricos e os problemas da mensuração prática. Economia e Desenvolvimento, 16, 22-41.

\footnotetext{
i Utilizaremos o termo "campo" entre aspas. Não estamos convencidas ainda de que é o mais adequado para tratar das pluralidades que se apresentam fora do urbano por isso a opção na forma de apresentação.

ii O Clube de Roma foi uma associação livre de cientistas, empresários e políticos de diversos países que se reuniu em Roma no início dos anos de 1970 para refletir, formular e debater sobre o sistema global.
}

Doi:

http://dx.doi.org/10.5902/red.v0i16.3442

Montibeller-Filho, G. (1999). O mito do desenvolvimento sustentável: meio ambiente e custos sociais no moderno sistema produtor de mercadorias (Tese de Doutorado). Universidade Federal de Santa Catarina, Santa Catarina.

Nascimento, E. P. (2012). Trajetória da sustentabilidade: do ambiental ao social, do social ao econômico. Estudos Avançados, 26(74), 51-64. Doi: https://dx.doi.org/10.1590/S010340142012000100005

Nobre, M., \& Amazonas, M. C. (2002). Desenvolvimento sustentável: a institucionalização de um conceito. Brasília: Ibama.

Sachs, I. (2000). Caminhos para o desenvolvimento sustentável. Rio de Janeiro, RJ: Garamound.

Sauvé, L. (2005). Educação ambiental: possibilidades e limitações. Educação $e$ Pesquisa, 31(2), 317-322.

\footnotetext{
Como citar este artigo / How to cite this article / Como citar este artículo:

APA:

Araújo, J. P., Assis, M. P., \& Costa, E. R. (2017). A sustentabilidade, a educação ambiental e o curso de Educação do Campo: é possível essa aproximação? Rev. Bras. Educ. Camp., 2(3), 921-940. DOI: http://dx.doi.org/10.20873/uft.25254863.2017v2n3p921

ABNT:

ARAÚJO, J. P.; ASSIS, M. P.; COSTA, E. R. A sustentabilidade, a educação ambiental e o curso de Educação do Campo: é possível essa aproximação? Rev. Bras. Educ. Camp., Tocantinópolis, v. 2, n. 3, p. 921-940, $2017 . \quad$ DOI: http://dx.doi.org/10.20873/uft.2525-

4863.2017v2n3p921
}

Recebido em: 24/07/2017 Aprovado em: 09/08/2017 Publicado em: 13/12/2017 
Araújo, J. P., Assis, M. P., \& Costa, E. R. (2017). A sustentabilidade, a educação ambiental e o curso de Educação do Campo...

\section{ORCID}

Juliana Pereira de Araújo

(iD) http://orcid.org/0000-0002-7705-028X

Maria Paulina de Assis

http://orcid.org/0000-0003-0295-1697

Elis Regina da Costa

http://orcid.org/0000-0002-4690-3702 